\title{
24 issues per year, 25 member societies, 1.5 million podcast listens and 6.5 million YouTube views
}

\author{
Karim M Khan, ${ }^{1,2}$ Babette M Pluim, ${ }^{3}$ Kay M Crossley ${ }^{4}$
}

When the current editorial team was given the privilege and responsibility of leading the BJSM into the 2010s, part of the job description was to write a 'Warm Up' for each of the 12 annual issues. We have dodged that responsibility pretty consistently and still get paid. However, at the end of our 10th year in the role we share 10 Level 5 opinions.

1. BJSM aims to serve the clinical community. This resulted from our 'listening for direct' consultations in 2008. It meant that BJSM differentiated itself from leading physiological journals such as Journal of Applied Physiology and also from surgical journals such as the American Journal of Sports Medicine. $B J S M$ was for clinicians who treat those in the physical activity, exercise and sporting community and those who use physical activity, exercise and sport as medicine.

2. 25 member societies make up the current 'BJSM family' without including 'the special' relationships we have with organisations such as the International Olympic Committee, the World Confederation of Physical Therapy, the Concussion in Sport Group (CISG), the International Federation of Sports Physical Therapy etc. The value proposition is that by being a full BJSM member, a clinical society gets BJSM support for conference promotion, social media consulting, full journal access at a greatly reduced rate for all members, and a say at the annual BJSM consultation with other member societies. Not a member yet but have a well

${ }^{1}$ Department of Family Practice, The University of British Columbia, Vancouver, Canada

${ }^{2}$ School of Kinesiology, University of British Columbia, Vancouver, BC, Canada

${ }^{3}$ Sports Medicine, Royal Netherlands Lawn Tennis Association, Amersfoort, The Netherlands

${ }^{4}$ School of Allied Health, La Trobe University, Melbourne, Victoria, Australia

Correspondence to Karim M Khan, Department of Family Practice, The University of British Columbia, Vancouver, V6T 1Z3, Canada; karim.khan@ubc.ca organised society? Contact our Publisher Janet O'Flaherty (joflaherty@bmj.com)

3. Conferences have multiplied in 2018. Our community now benefits from many, many more quality conferences and professional education opportunities than when we were learning sports medicine and sports physiotherapy. The IOC World Congress on Prevention of Illness and Injury in Sport is one example (next held in Monaco, March 2020). A 2019 highlight is the third World Congress of Sports Physical Therapy (Vancouver, October 4-5, 2019, figure 1). Next year you can attend Camp Nou, the home of FC Barcelona on May 4-6 as for the $26^{\text {th }}$ iteration of Isokinetic's very successful football education programme as featured on the cover of this issue of BJSM. (figure 2) Unfortunately, as in any field, scammers are trying to make money from the unaware and the preponderance of predator journals and predator conferences are a blight on our field. The 'BJSM approved' logo (figure 3 ) provides one level of insurance that you are attending a real conference-not a fake.

4. 'When did you know you had won?' is a clichéd reporter's question at elite sporting events. BJSM isn't trying to win, but we have goals to allow us to make decisions and we feel our community has benefited from BJSM's improved impact factor, social media reach, service to member societies (as above) and a responsible governance (stability, planning ahead, conference sponsorship, new product development such as BMJ Open Sport and Exercise Medicine)

5. BMJ Open Sport and Exercise Medicine publishes 100 papers a year and provides a trusted Open Access journal platform. Peer review is speedy and submissions flow

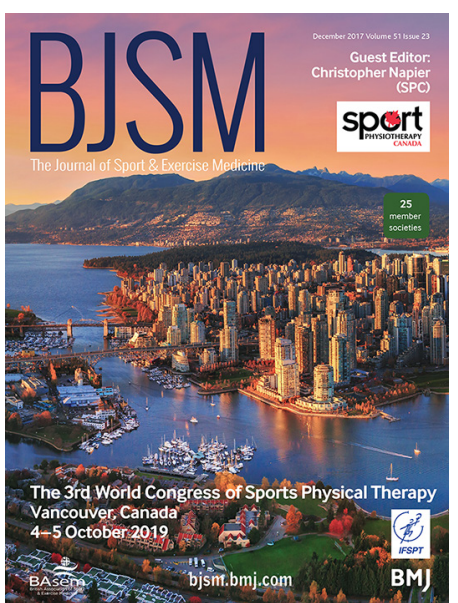

Figure 1 Sport Physiotherapy Canada will host successful bid for the 3rd World Congress in Sports Physical Therapy in October 2019.

conveniently, for BJSM submissions that have to be passed over. BJSM has an $8 \%$ acceptance rate from 1500 papers annually.

6. We have seen massive improvements in the quality of BJSM papers.

Specifically, methods are much much stronger. Stronger designs, larger numbers, more appropriate analysis, judicious (concise) writing with explicit research limitations. Thanks to leaders of the BJSM Working and Innovation groups (WIGs) and all levels of the Editorial Board.

7. Sexism. At a time when sexual harassment and failure to embrace diversity demands attention we must take careful stock of our own house. It's a time to reflect and audit. What can we do to be part of the solution? We can, and must, do

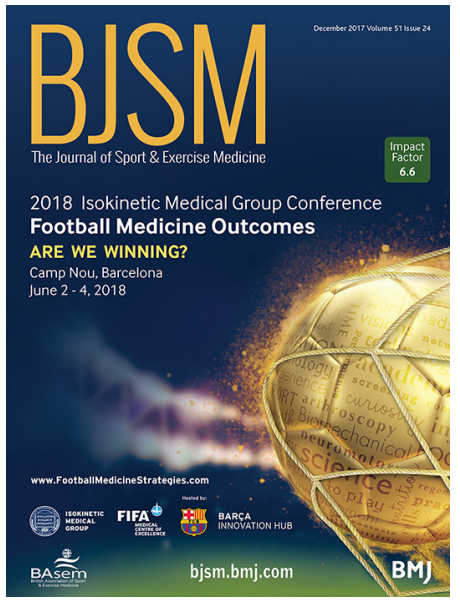

Figure 2 Camp Nou-the iconic home of FC Barcelona, is the venue for 2018's largest football conference. 


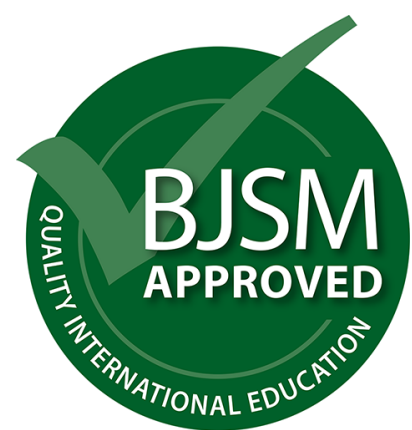

Figure 3 'BJSM approved' logos: battling against predatory conference marketers.

better to reflect BMJ group values relating to diversity.

8. Food. 'You cannot outrun a bad diet' http://bjsm.bmj.com/content/49/15/ 967 got a lot of attention and some wondered why BJSM was in the food research business. Our editor in chief contends that BJSM is not beholden to the agriculture industry, the food industry or to special interest groups. We are open to debate. Should BJSM leave the issue of healthy weight and obsesity alone and trust national food guides? Should we trust industry to place the public's interest above shareholder profit?

9. New BJSM sections aim to tempt the reader to spend more time on $B J S M$ than he or she really should. "Bright spots" for programs that work - in public health and in the musculoskeletal system; Mobile App Reviews; Inside Track interviews to learn the personal success secrets of leaders in our field; PEDro summaries to get to the essence of effective Sports Physiotherapy; Educational reviews of Continuing Education courses and our section of Education from other journals. More feature sections to come in 2018 (with some colour tabs!) and we will share these innovations via the BJSM blog.

10. Our suite of social media channels. Returning to the 2008 Editors' contract, there was no mention of social medial. 12 'Warm Up's a year but no Twitter, Facebook, YouTube, podcasts or Mobile App. No BJSM blog. Thanks for engaging with those elements of BJSM. We plan to make them even more valuable for you, our clinical community, in 2018 and beyond. Enjoy issue 24 and we'll highlight 'this issue' on the Blog and social channels.

Competing interests BJSM Editors receive an honorarium. BJSM editors have had conference travel, meals, accommodation paid for by various conferences including the Isokinetic Conference. Karim Khan is on the Scientific Advisory Committee for the Isokinetic Conference and considers himself a friend of Stefano Della Villa.

Provenance and peer review Commissioned; internally peer reviewed.

(c) Article author(s) (or their employer(s) unless otherwise stated in the text of the article) 2017. All rights reserved. No commercial use is permitted unless otherwise expressly granted.

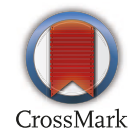

To cite Khan KM, Pluim BM, Crossley KM. Br J Sports Med 2017;51:1711-1712.

Br J Sports Med 2017;51:1711-1712. doi:10.1136/bjsports-2017-098785 